\title{
EL USO DE LOS MOLUSCOS MARINOS POR LOS CAZADORES-RECOLECTORES PAMPEANOS
}

\author{
THE USE OF MARINE SHELLFISH BY \\ PAMPEAN HUNTER-GATHERERS
}

\author{
Mariano Bonomo ${ }^{1}$
}

\begin{abstract}
En numerosos contextos arqueológicos de la región pampeana (Argentina), con cronologías que abarcan del Pleistoceno Final al Holoceno Tardío, se han recuperado moluscos sin modificación antrópica y cuentas sobre valvas marinas. En parte de las investigaciones desarrolladas a lo largo del siglo XX en el litoral marítimo pampeano se ha propuesto la presencia de grupos costeros con una economía basada en el consumo de moluscos. Sin embargo, por el momento no se ha corroborado si estos potenciales recursos fueron una fuente frecuente de alimento para las poblaciones del pasado. En este trabajo se analiza la bibliografía existente y se discute cómo pudieron ser utilizados los moluscos marinos por los cazadores-recolectores pampeanos. Sobre la base de la información presentada se sostiene que la utilización de los moluscos en la región pampeana no posee una clara vinculación con la dieta y que gran parte de estos elementos probablemente tuvieron un fuerte significado simbólico.
\end{abstract}

Palabras claves: región pampeana, cazadores-recolectores, moluscos marinos.

Numerous archaeological contexts of the Pampean Region (Argentina), with chronologies that range from Final Pleistocene to Late Holocene, have yielded shells without human modification as well as beads made from valves. Some of the research developed throughout the 20th century on the Pampean marine coast has proposed that coastal groups had an economy based on shellfish consumption. Nevertheless, at present, it has not been corroborated if these potential resources were a frequent food source for past populations. Analyzing the available literature, this paper discusses how marine shellfish could have been used by Pampean hunter-gatherers. On the basis of this information, it is argued that shellfish used in the Pampean Region do not have a clear link with diet and that they may had a strong symbolic meaning.

Key words: Pampean Region, hunter-gatherers, marine shellfish.

La información arqueológica acerca de la ocupación humana del litoral atlántico sudamericano muestra que en determinadas zonas costeras existen abundantes datos que señalan el consumo de moluscos marinos a partir del Holoceno Medio, momento en que se estabilizan el nivel mundial del mar y los ambientes costeros. Estas evidencias se presentan en el litoral continental en los sambaquíes distribuidos desde el Estado de Rio de Janeiro hasta el de Santa Catarina en el sur de Brasil (Figuti 1993; Lima 1999-2000), en los concheros de Uruguay (Castiñeira et al. 2004), del norte y el sur de la Patagonia (Bórmida 1969; Moreno 2003; Sanguinetti de Bórmida 1999). A su vez, en el extremo sur del continente, en el Canal de Beagle habitaron poblaciones con una subsistencia basada en la explotación de fauna marina y con medios tecnológicos para estos propósitos, como canoas y arpones de punta separable (Orquera y Piana 1999). A diferencia del sector atlántico, la costa del Océano Pacífico de Sudamérica registra ocupaciones arqueológicas del Pleistoceno Final-Holoceno Temprano que muestran el aprovechamiento de importantes cantidades de moluscos marinos (Jackson y Báez 2005; Llagostera 1992; Sandweiss et al. 1998).

Las primeras investigaciones arqueológicas del litoral atlántico pampeano se iniciaron a fines del siglo XIX y principios del XX. Desde estos primeros trabajos se ha propuesto que los moluscos marinos fueron una fuente de alimento para las poblaciones del pasado. Algunos autores (Ameghino 1909; Bórmida 1969; Mesa y Conlazo 1982) han sostenido el desarrollo de sociedades exclusivas del hábitat costero que estarían adaptadas en distinto grado a la explotación de

1 CONICET-Departamento Científico de Arqueología, Facultad de Ciencias Naturales y Museo, UNLP. Paseo del Bosque s/n, 1.900 La Plata, Argentina. mbonomo@ fcnym.unlp.edu.ar 
recursos litorales, principalmente moluscos. Sin embargo, la idea de que los moluscos marinos fueron aprovechados con fines alimentarios se ha mantenido como una hipótesis que no ha sido evaluada en profundidad con estudios específicos. El objetivo de este artículo es discutir esta hipótesis. Mediante una revisión bibliográfica de los sitios con moluscos marinos se evalúa cómo pudieron ser utilizados y qué relación tuvieron con la economía y aspectos sociales e ideacionales de los cazadores-recolectores pampeanos. Para ello se analizan la disponibilidad y el hábitat de las especies que se encuentran en el registro arqueológico regional, las propiedades de sus exoesqueletos, la distribución espacial de los sitios, los contextos de depositación y los posibles modos de aprovisionamiento de estos invertebrados marinos.

\section{Distribución Espacial y Temporal de los Moluscos Marinos en el Registro Pampeano}

En primer lugar, es necesario tener presente la distribución a nivel regional de los elementos procedentes de la costa. En numerosos sitios arqueológicos de la región pampeana se han recuperado artefactos manufacturados en materias primas líticas costeras y moluscos marinos. Las rocas costeras están constituidas por rodados de origen principalmente volcánico (basalto, andesita, riolita) que en general no superan los $10 \mathrm{~cm}$ de largo máximo. Estos clastos redondeados, con superficies naturales finamente pulidas por la acción marina, provienen de depósitos secundarios distribuidos a lo largo de las playas del litoral marítimo pampeano (Bonomo 2004, 2005). Moluscos en estado natural (sin modificación antrópica) y cuentas sobre valvas marinas han sido registrados en 31 ocupaciones $^{1}$ del interior pampeano, de las cuales se muestran en la Tabla 1 sólo aquellas en las que fue establecida su cronología. Los contextos arqueológicos donde se recuperaron moluscos marinos corresponden a sitios donde se han realizado actividades múltiples y específicas y que tienen una distribución temporal que abarca desde el Pleistoceno Final-Holoceno Temprano al Holoceno Tardío.

Es importante anticipar una serie de limitaciones que presenta parte de la información bibliográfica utilizada en este trabajo. Gran parte de los conjuntos con moluscos fueron recuperados en posición superficial o no poseen dataciones cronológicas absolutas. Además, en varios de los trabajos sólo se menciona la presencia de especies de moluscos sin incluir fotografías, datos cuantitativos o de la disposición espacial de los mismos y las ilustraciones de los elementos propuestos como artefactos son escasas. Así, el registro de moluscos es insatisfactorio, existiendo abundante información arqueológica y biológica que no ha sido evaluada de manera íntegra y que puede brindar una visión más acabada sobre el tema del consumo o no de moluscos marinos en la región pampeana.

En general los moluscos marinos se presentan en densidades muy bajas en los sitios pampeanos. En los conjuntos arqueológicos incluidos en la Tabla 1 se observa que en la mayoría no fueron recuperados más de 10 restos de moluscos $(n=16$ ocupaciones) y que gran parte de los mismos están fragmentados. Las ocupaciones que muestran mayor cantidad de moluscos son las de los sitios Paso Otero 3, Arroyo Seco 2 y Chenque I. De estos tres sitios, los que muestran mayor número son los dos últimos, en los que los moluscos están representados fundamentalmente por cuentas sobre valva asociadas a esqueletos humanos en contextos mortuorios (véase más adelante).

Los moluscos marinos y los rodados procedentes de la costa se hallan con frecuencia en sitios ubicados fuera de la línea de médanos litorales. En la Figura 1 fueron agrupadas las ocupaciones del interior que presentan sólo rodados costeros, sólo moluscos o ambos elementos en función de la distancia a la costa ${ }^{2}$. En la misma se observa que la mayoría de las ocupaciones con rodados y/o moluscos se encuentran entre los 3,5 y $70 \mathrm{~km}$, aunque sobresale de forma clara un pico que muestra un aumento de las frecuencias entre los 40 y $50 \mathrm{~km}$. Luego de los $70 \mathrm{~km}$ los conjuntos con estos elementos son más escasos. Sin embargo, es interesante remarcar que mientras la explotación de las rocas costeras no se registra en las cuatro ocupaciones a más de $190 \mathrm{~km}$ del litoral, la superficie donde se distribuyen los moluscos es más extensa dado que los mismos continúan registrándose hasta los $450 \mathrm{~km}$ de la costa ${ }^{3}$.

De lo anterior, lo que se pretende remarcar es que el registro de moluscos marinos en la región pampeana no es exclusivo del litoral marítimo. Los sitios con gastrópodos y bivalvos poseen una am- 
Tabla 1. Ocupaciones arqueológicas de los principales sitios del interior pampeano del Pleistoceno Final-Holoceno en las que han sido recuperados distintos taxa de moluscos marinos. Frag. $=$ fragmento(s). ${ }^{*}$ Los moluscos hallados en este sitio también podrían provenir del Océano Pacífico (Berón 2004).

Archaeological occupations of the main inland Pampean sites of the Late Pleistocene-Holocene in which different taxa of marine shellfish have been recovered. Frag. =fragment(s). *The shellfish found on this site could have come from the Pacific Ocean (Berón 2004).

\begin{tabular}{|c|c|c|c|c|c|}
\hline $\begin{array}{l}\text { Sitio arqueológico } \\
\text { (ocupación) }\end{array}$ & $\begin{array}{c}\text { Superficie } \\
\text { del sitio }\left(\mathrm{m}^{2}\right)\end{array}$ & $\begin{array}{l}\text { Edad a.p. } \\
\text { (estimada) }\end{array}$ & Moluscos marinos & $\begin{array}{l}\text { Distancia a } \\
\text { la costa }(\mathrm{km})\end{array}$ & Fuentes \\
\hline $\begin{array}{l}\text { Arroyo Seco } 2 \\
\text { (Comp. Inferior) }\end{array}$ & 243,2 & $12,2-8,3 \mathrm{ka}$ & $\begin{array}{l}\text { Adelomelon brasiliana } \\
(\mathrm{n}=1 \text { frag.) }\end{array}$ & 60 & Politis (1984) \\
\hline $\begin{array}{l}\text { La Toma } \\
\text { (Comp. Medio? e Inferior) }\end{array}$ & 56 & $5,5-3,8 \mathrm{ka}$ & $\begin{array}{l}\text { Volutidae indet. ( } \mathrm{n}=4 \text { frag.), } \\
\text { Pecten sp. }(\mathrm{n}=1)\end{array}$ & 40 & Madrid y Politis (1991) \\
\hline Paso Otero 3 & 24 & $4,7-4,5 \mathrm{ka}$ & $\begin{array}{l}\text { Adelomelon ancilla }(\mathrm{n}=2 \text { frag. }) \text {, } \\
\text { Mollusca indet. }(\mathrm{n}=55)\end{array}$ & 50 & Martínez (1999) \\
\hline $\begin{array}{l}\text { Arroyo Seco } 2 \\
\text { (Comp. Medio) }\end{array}$ & 243,2 & $7,8-6,3 \mathrm{ka}$ & $\begin{array}{l}\text { Amiantis sp. }(\mathrm{n}=1) \\
\text { Mollusca indet }(>220)\end{array}$ & 60 & Politis (1984) \\
\hline SA 17 Avestruz & - & $3,2 \mathrm{ka}$ & Volutidae indet. $(\mathrm{n}=$ ?) & 90 & Austral et al. (1988) \\
\hline $\begin{array}{l}\text { Fortín Necochea } \\
\text { (Unid. C) }\end{array}$ & 35 & $6,0-3,6 \mathrm{ka}$ & $\begin{array}{l}\text { Amiantis purpurata y Mollusca } \\
\text { indet. ( } \mathrm{n}=4 \text { frag.) }\end{array}$ & 190 & $\begin{array}{l}\text { Crivelli Montero et al. } \\
\text { (1997) }\end{array}$ \\
\hline $\begin{array}{l}\text { Tapera Moreira } 1 \\
\text { (Comp. Inferior) }\end{array}$ & 17 & $4,5-2,2 \mathrm{ka}$ & Volutidae indet. $(\mathrm{n}=2)$ & 200 & Berón (2004) \\
\hline $\begin{array}{l}\text { Casa de Piedra } 1 \\
\text { (Ocup Intermedias) }\end{array}$ & 26,5 & $6,0 \mathrm{ka}$ & $\begin{array}{l}\text { Adelomelon brasiliana } \\
\text { ( } \mathrm{n}=1 \text { frag.) }\end{array}$ & $450 *$ & Gradín (1984) \\
\hline $\begin{array}{l}\text { Nutria Mansa } 2 \\
\text { Superficie }\end{array}$ & 200.000 & (H. Tardío) & Mollusca indet. ( $\mathrm{n}=1$ frag.) & 3,5 & Bonomo (2004) \\
\hline Laguna Sotelo & 17 & (H. Tardío) & Volutidae indet. $(\mathrm{n}=1)$ & 6 & $\begin{array}{l}\text { Eugenio y Aldazabal } \\
(1987-88)\end{array}$ \\
\hline Cueva del Tigre & 2 & (H. Tardío) & Mollusca indet. ( $\mathrm{n}=2$ frag.) & 9 & Madrid et al. (2002) \\
\hline $\begin{array}{l}\text { La Toma } \\
\text { (Comp. Superior) }\end{array}$ & 56 & $2,0-0,9 \mathrm{ka}$ & $\begin{array}{l}\text { Adelomelon brasiliana }(\mathrm{n}=1) \\
\text { Zidona dufresnei }(\mathrm{n}=1)\end{array}$ & 40 & Madrid y Politis (1991) \\
\hline Cueva El Abra & 9 & (H. Tardío) & Mollusca indet. $(n=3)$ & 40 & $\begin{array}{l}\text { Mazzanti y Quintana } \\
\text { (2001) }\end{array}$ \\
\hline $\begin{array}{l}\text { Cueva Tixi } \\
\text { (4ta ocup.) }\end{array}$ & 15 & $0,7-0,1 \mathrm{ka}$ & $\begin{array}{l}\text { Drupa pilsbry, Drupa sp. }(\mathrm{n}=4) \\
\text { Vivalvia indet. }(\mathrm{n}=1) \\
\text { Mollusca indet. }(\mathrm{n}=3)\end{array}$ & 40 & $\begin{array}{l}\text { Mazzanti y Quintana } \\
\text { (2001) }\end{array}$ \\
\hline $\begin{array}{l}\text { Arroyo Seco } 2 \\
\text { (Comp. Superior) }\end{array}$ & 243,2 & (H. Tardío) & Mollusca indet. (> de 75) & 60 & Politis (1984) \\
\hline San Martín 1 & 15 & (H. Tardío) & $\begin{array}{l}\text { Adelomelon brasiliana }(\mathrm{n}=5 \\
\text { frag.), Volutidae indet. }(\mathrm{n}=\text { ?), } \\
\text { Mollusca indet. }(\mathrm{n}=2)\end{array}$ & 80 & Oliva et al. (1990) \\
\hline Laguna Los Chilenos 1 & 21 & $0,4 \mathrm{ka}$ & $\begin{array}{l}\text { Adelomelon brasiliana }(\mathrm{n}=1 \\
\text { frag.), Mollusca indet. }(\mathrm{n}=9)\end{array}$ & 90 & Barrientos et al. (1997) \\
\hline Fortín Necochea superficie & 200.000 & (H. Tardío) & Amiantis purpurata $(\mathrm{n}=1$ frag.) & 190 & $\begin{array}{l}\text { Crivelli Montero et al. } \\
(1987-88)\end{array}$ \\
\hline $\begin{array}{l}\text { Tapera Moreira } 1 \\
\text { (Comp. Superior y Medio) }\end{array}$ & 17 & $2,1-0,5 \mathrm{ka}$ & Volutidae indet. $(\mathrm{n}=2)$ & 200 & Berón (2004) \\
\hline $\begin{array}{l}\text { Don Aldo } \\
\text { Superficie }\end{array}$ & 3.200 & (H. Tardío) & $\begin{array}{l}\text { Adelomelon } \mathrm{sp} .(\mathrm{n}=1) \\
\text { Volutidae indet. }(\mathrm{n}=1 \text { frag. })\end{array}$ & 260 & Politis et al. (2003) \\
\hline $\begin{array}{l}\text { Chenque I } \\
\text { (Unid. Inf y Sup) }\end{array}$ & 210,4 & $1,0-0,8 \mathrm{ka}$ & $\begin{array}{l}\text { Urosalpinx haneti }(\mathrm{n}=49), \text { Buc- } \\
\text { cinanops } \mathrm{sp} .(\mathrm{n}=1) \text {, Fisurella } \mathrm{sp} \text {. } \\
(\mathrm{n}=104) \text {, Amiantis purpurata } \\
(\mathrm{n}=1) \text {, Vivalvia indet. }(\mathrm{n}=27) \\
\text { Mollusca indet. }(>700)\end{array}$ & 300 & Berón (2004) \\
\hline
\end{tabular}




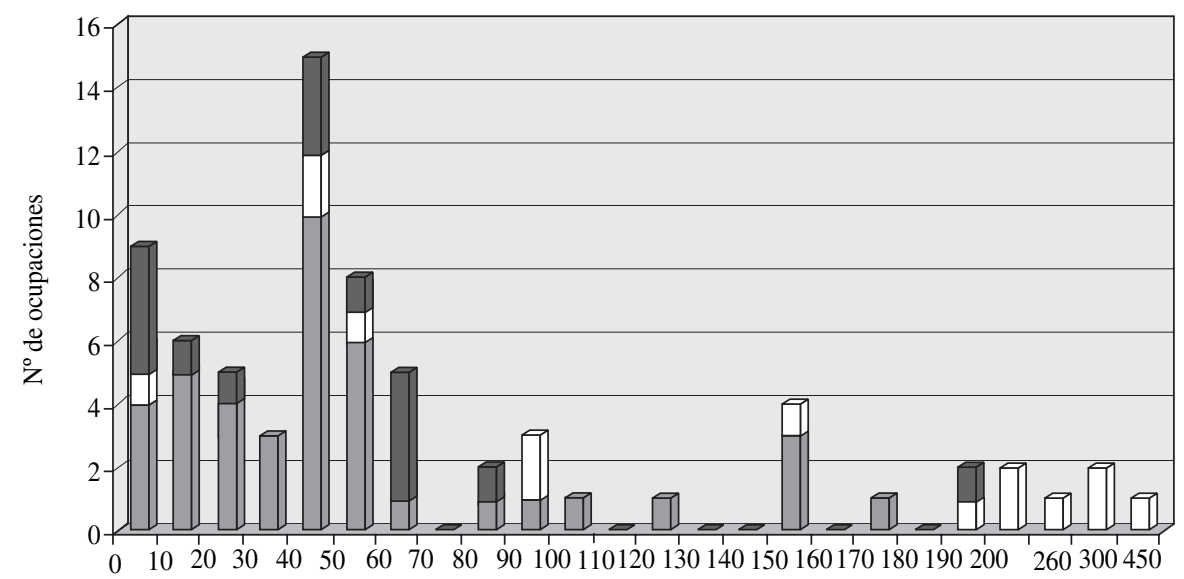

Distancia a la costa

Sólo rodados $\square$ Sólo moluscos

Rodados y moluscos

Figura 1. Frecuencias absolutas de ocupaciones arqueológicas del interior pampeano con presencia de rodados costeros y/o moluscos marinos con relación a la distancia al litoral marítimo.

Absolute frequencies of the inland Pampean archaeological occupations with coastal cobbles and/or marine shellfish in relation to the distance from the marine coast.

plia distribución geográfica (diferentes áreas pampeanas) y temporal (desde el Pleistoceno Final al Holoceno Tardío), lo cual muestra que estos elementos marinos circularon ampliamente por el paisaje pampeano, probablemente, como bienes de intercambio (Figura 2).

\section{Propuestas Acerca de la Utilización de los Moluscos Marinos}

En la década de 1960, Bórmida (1969) realizó investigaciones arqueológicas en Norpatagonia, donde caracterizó la industria costera "Puntarrubiense" constituida por instrumentos (mayoritariamente raederas simples y múltiples) obtenidos por la aplicación de la técnica de talla y retoque bipolar sobre rodados costeros de basalto. Debido a su asociación con concheros, estos conjuntos superficiales norpatagónicos indicaban la existencia de grupos étnicos propios del litoral con una economía especializada en la explotación de moluscos marinos. De acuerdo a la composición artefactual de los sitios arqueológicos, a su ubicación topográfica y a la cronología asignada a las distintas cotas de los sistemas de terrazas marinas patagónicas, Bórmida propuso que su desarrollo temporal abarcaría desde los 2.000 años a.C. hasta el período hispano-indígena. Con sus estudios en la costa norpatagónica este investigador proyectó las características del registro arqueológico de esa zona a los sitios de la faja de médanos del área Interserrana, comprendida entre los Sistemas Serranos de Tandilla y Ventania. Aun cuando no había desarrollado investigaciones específicas en la costa pampeana, fue más allá del río Colorado (límite entre Pampa y Patagonia) proponiendo que la industria "Puntarrubiense" pertenecía a grupos que habitaban a lo largo de la costa que se extendía entre la desembocadura del río Negro y la zona rocosa de Cabo Corrientes (Figura 3). Las afinidades culturales de ambas zonas litorales, norpatagónica y pampeana, se fundamentaban en similitudes cronológicas y de la tecnología lítica asociada con la reducción bipolar de rodados costeros. De esta forma, se aislaba a los contextos costeros de los del interior pampeano ya que estos últimos mostraban el aprovechamiento de rocas serranas (sobre todo cuarcita y ftanita) por cazadores focalizados en la fauna terrestre.

El hallazgo de concentraciones de bivalvos asociadas con restos culturales en la costa norpatagónica fue empleado como sustento empírico de que estas poblaciones asentadas en el litoral estaban adaptadas a la explotación intensiva de esos 


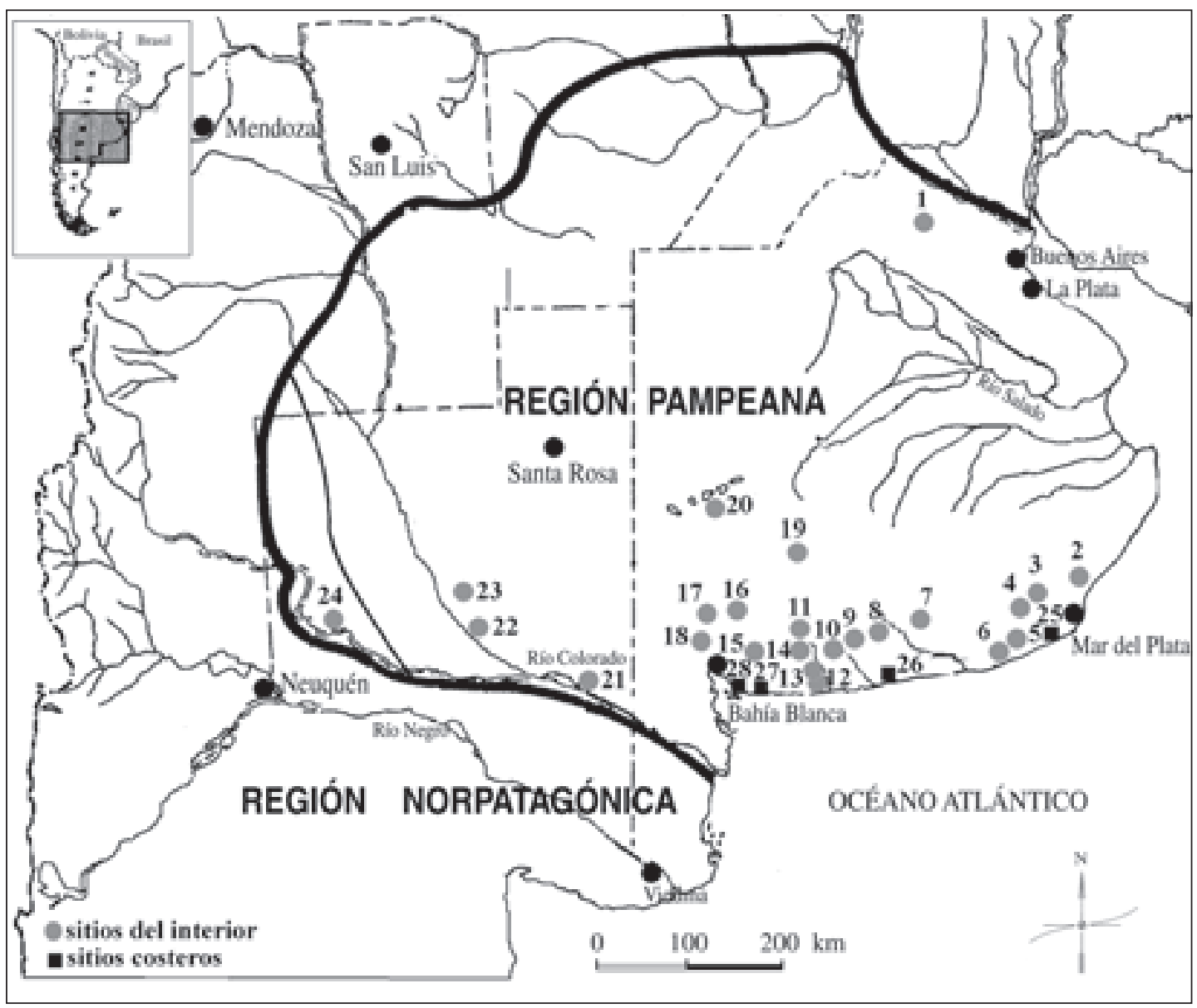

Figura 2. Distribución geográfica de los principales sitios arqueológicos de la región pampeana con moluscos marinos. Referencias: sitios del interior: (1) Fontezuelas; (2) Laguna Sotelo; (3) Cueva El Abra; (4) Cueva Tixi; (5) Nutria Mansa 1 sup; (6) Nutria Mansa 2 sup; (7) Quequén Chico 1; (8) Paso Otero 3; (9) Arroyo Seco 1; (10) Arroyo Seco 2; (11) Puente de Oriente; (12) Sur Cueva del Tigre; (13) Cueva del Tigre; (14) Norte Cueva del Tigre; (15) La Toma; (16) SA Avestruz 17; (17) Laguna Los Chilenos; (18) San Martín 1; (19) Fortín Necochea; (20) Pintado II; (21) Don Aldo; (22) Tapera Moreira; (23) Chenque I; (24) Casa de Piedra 1; sitios costeros (25) Bellamar 1 y 3; (26) Balneario Orense; (27) El Palomar 1 y El Puente 1; (28) La Olla 1.

Geographical distribution of the main archaeological sites of the Pampean region with marine shellfish. References: Inland sites: (1) Fontezuelas; (2) Laguna Sotelo; (3) Cueva El Abra; (4) Cueva Tixi; (5) Nutria Mansa 1 sup; (6) Nutria Mansa 2 sup; (7) Quequén Chico 1; (8) Paso Otero 3; (9) Arroyo Seco 1; (10) Arroyo Seco 2; (11) Puente de Oriente; (12) Sur Cueva del Tigre; (13) Cueva del Tigre; (14) Norte Cueva del Tigre; (15) La Toma; (16) SA Avestruz 17; (17) Laguna Los Chilenos; (18) San Martín 1; (19) Fortín Necochea; (20) Pintado II; (21) Don Aldo; (22) Tapera Moreira; (23) Chenque I; (24) Casa de Piedra 1; Coastal sites: (25) Bellamar 1 y 3; (26) Balneario Orense; (27) El Palomar 1 y El Puente 1; (28) La Olla 1.

moluscos. Esta idea se basaba en las mayores proporciones de desperdicios de moluscos preservados en relación con otros recursos animales, como por ejemplo pinnípedos tal como fuera observado más tarde para el Canal de Beagle (Orquera y Piana 1999). Es importante tener en cuenta que el aprovechamiento de moluscos posee ciertas ventajas, entre las que se destacan, por un lado, el hecho de que sus bancos están disponibles a lo largo de todo el año en lugares puntuales que son loca- lizados fácilmente. Por el otro, que la recolección puede ser efectuada por la mayoría de los miembros de una población sin una tecnología específicamente diseñada para su obtención, como puede suceder con los peces (anzuelos, redes) o los lobos marinos (arpones) (Orquera y Piana 1999; Perlman 1980; Yesner 1980). Estos factores pueden haber favorecido su explotación en la costa norpatagónica, aunque no parece ocurrir lo mismo en el litoral marítimo pampeano. 


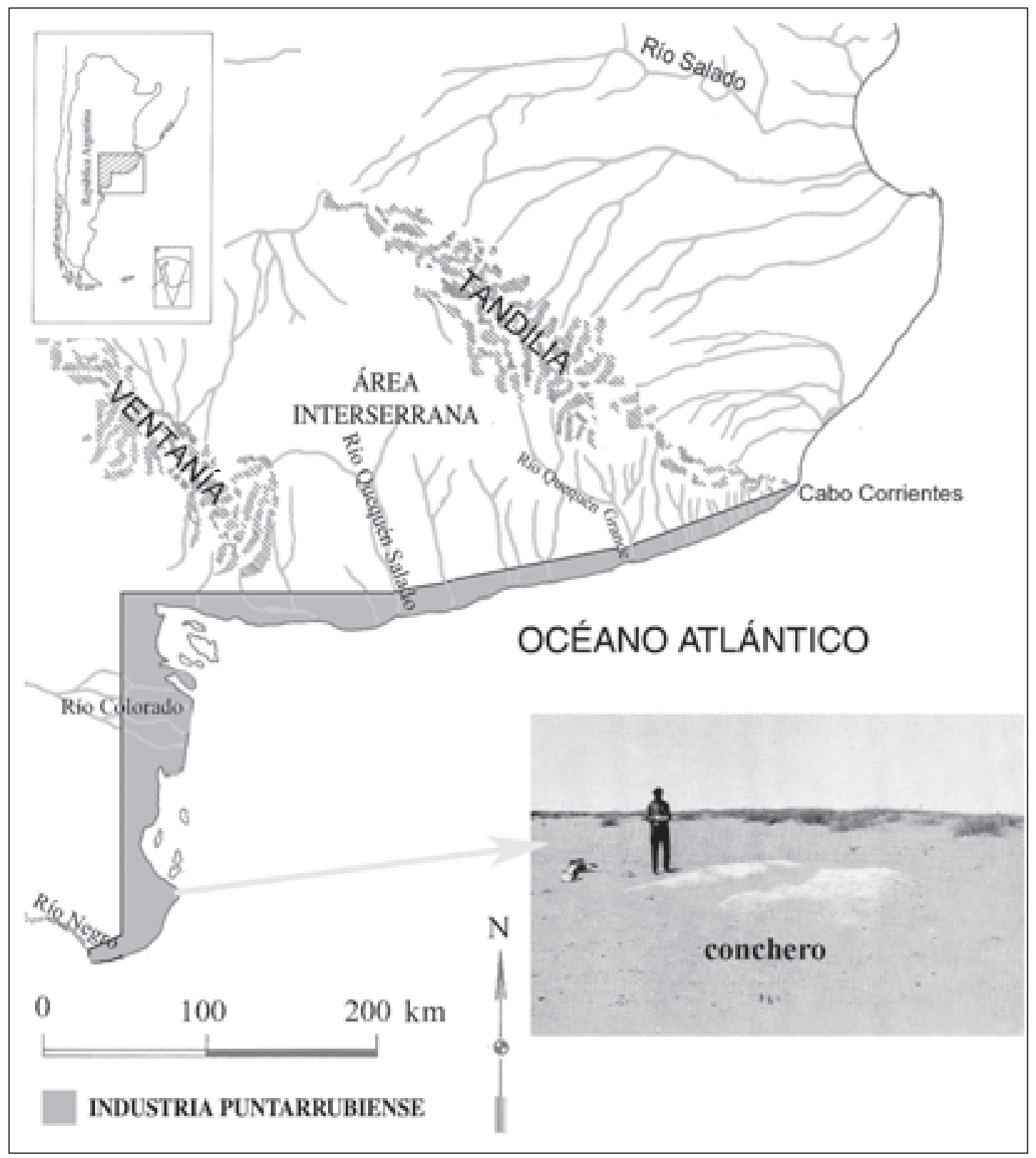

Figura 3. Área de distribución de la industria Puntarrubiense definida por Bórmida, asociada con poblaciones humanas con una economía focalizada en la explotación de moluscos marinos (fotografía de conchero modificada de Bórmida 1969). Area of distribution of the Puntarrubiense industry defined by Bórmida associated with human populations with an economy focused on the exploitation of marine shellfish (photograph of shellmound modified from Bórmida 1969).

En los sitios arqueológicos localizados en la cadena de médanos del área Interserrana se ha sugerido el consumo de moluscos (Ameghino 1909; Frenguelli 1921; Loponte y Acosta 1986). Otros autores (Austral 1968; Díaz de Chiri 1977; Mesa y Conlazo 1982) que trabajaron en la costa pampeana identificaron en los conjuntos artefactuales a la industria Puntarrubiense definida por Bórmida, por lo que implícitamente estaban aludiendo a la explotación de moluscos. Esta asignación cultural se basaba en el hallazgo de sitios superficiales constituidos por numerosos productos bipolares sobre rodados costeros, es decir, se fundaba en un criterio tecnológico, sin evaluar en profundi- 
dad aspectos de la subsistencia o la cronología de las ocupaciones. También Crivelli Montero y colaboradores (1997) sostuvieron el aprovechamiento de moluscos por los grupos del interior.

$\mathrm{Al}$ igual que en la gran mayoría de los sitios del interior, en los contextos arqueológicos de la costa pampeana los moluscos marinos poseen una baja frecuencia. Se ha mencionado el hallazgo de valvas aisladas en algunos sitios superficiales de la faja de médanos adyacente al sector de playa, aunque en la mayoría de los casos no es posible establecer de manera precisa su grado de asociación contextual con los objetos arqueológicos y menos aún que estos elementos representen desperdicios de la alimentación humana. Inclusive teniéndolos en cuenta, estos conjuntos muestran que, en general, los moluscos marinos poseen una muy baja densidad. Por ejemplo, en el sitio en posición superficial El Palomar 1 se hallaron cinco ejemplares de Adelomelon brasiliana y tres de Arca bisulcata en un área aproximada de 3.420 $\mathrm{m}^{2}$ y en el sitio El Puente 1 se recuperó un fragmento de Adelomelon brasiliana en $1.420 \mathrm{~m}^{2}$ (Austral 1965). En los sitios superficiales Bellamar 1 y Bellamar 3 se registró un resto de molusco en cada uno en $2.300 \mathrm{~m}^{2}$ y $31.040 \mathrm{~m}^{2}$, respectivamente (Bonomo 2004). Sólo se ha dado a conocer una acumulación superficial de valvas en las inmediaciones del Balneario Orense junto a la cual fueron recuperados materiales líticos. Sin embargo, no está claro el carácter antrópico o natural de este único hallazgo (Loponte 1987). A su vez, en el sitio costero en posición estratigráfica La Olla 1, donde se ha demostrado la explotación de mamíferos marinos, únicamente fueron recuperados dos ejemplares de Adelomelon brasiliana en $50 \mathrm{~m}^{2}$ excavados (Politis et al. 1994). En síntesis, al contrario de lo que sucede en Norpatagonia, no se han detectado concheros que impliquen una recolección de importantes cantidades de moluscos en el litoral pampeano (Politis 1984).

\section{Evaluación de la Utilización de los Moluscos Marinos por los Cazadores-Recolectores Pampeanos}

La recolección manual de moluscos vivos, sin tener en cuenta la utilización de técnicas de buceo, pudo haberse realizado rápidamente y con poco esfuerzo en la playa durante las mareas bajas. Para evaluar la hipótesis de que los moluscos marinos han sido una fuente de alimento para las poblaciones pampeanas se debe considerar la disponibilidad de las especies que viven en la zona intermareal en el litoral bonaerense y si las mismas se registran en los contextos arqueológicos. Previamente, es necesario tener en cuenta que los cambios en el nivel del mar ocurridos desde el Pleistoceno Final en la región pampeana pueden haber modificado la distribución de los mariscos que habitaban aguas poco profundas. Esto pudo deberse al enfriamiento de las aguas marinas luego del Óptimo Climático del Holoceno Medio registrado hace 7.500-7.000 años o a variaciones en la naturaleza del sustrato, pendiente y energía. Sin embargo, los datos sobre las oscilaciones del nivel marino en la región son aún demasiado generales como para estimar en qué medida fue afectada la ecología de los moluscos. Aun así, la información paleobiogeográfica existente para la costa bonaerense (Aguirre y Farinati 2000) indica que la malacofauna de los depósitos marinos holocénicos es similar a la actual en cuanto a la composición de especies, mostrando algunas diferencias cuantitativas con los ejemplares modernos. Entonces, esto indica que los bivalvos y gastrópodos hallados hoy en día estuvieron presentes durante el Holoceno. Además, la mayoría de los sitios con moluscos en los que fue establecida su cronología a través de fechados radiocarbónicos o estimada de acuerdo a la presencia de artefactos diagnósticos (puntas de proyectil y cerámica) o su posición estratigráfica (Tabla 1), son posteriores al momento en que se estabiliza la presente línea de costa entre los 6.000-5.000 años a.p. (Isla 1995).

Las evidencias de los sitios pampeanos con relación a las especies que actualmente habitan la zona supralitoral contrastan con los datos existentes para otros sectores costeros donde se ha verificado la explotación de bivalvos. Si se toma en cuenta la topografía actual de la costa bonaerense y que los taxa han variado fundamentalmente en abundancia en el Holoceno, es posible efectuar algunas consideraciones de alcance general. Las especies que habitan masas de aguas superficiales en las proximidades de la costa pampeana son aquellas pertenecientes a la Provincia Malacológica Argentina (Aguirre y Farinati 2000). Las principales especies con partes blandas comestibles que pudieron ser recolectadas en la zona de influencia de las mareas son los siguientes bivalvos: 
Tabla 2. Especies de bivalvos y gastrópodos marinos representadas en sitios arqueológicos costeros y del interior de la región pampeana.

Species of bivalves and gastropods represented in coastal and inland archaeological sites of the Pampean region.

\begin{tabular}{|c|c|c|c|}
\hline Bivalvos & $\begin{array}{l}\text { Longitud } \\
\text { máxima } \\
(\mathrm{mm})\end{array}$ & $\begin{array}{l}\text { Profundidad donde } \\
\text { viven }(\mathrm{m})\end{array}$ & Sitios arqueológicos \\
\hline Glycymeris longior & 40 & $10-20$ & Nutria Mansa 1 sup \\
\hline Arca bisulcata & 41 & $15-40$ & El Palomar sitio 1 \\
\hline Amiantis purpurata & 85 & $15-20$ & $\begin{array}{l}\text { Sitio Chenque I (material fósil), Fortín Necochea, } \\
\text { Cueva del Tigre } 4\end{array}$ \\
\hline Amiantis sp. & 58 & 20 & Arroyo Seco 2 \\
\hline Pecten sp. & 60 & $20-130$ & La Toma \\
\hline Bivalvia indet. & - & - & Fontezuelas, Cueva Taxi \\
\hline Gastrópodos & $\begin{array}{l}\text { Altura } \\
\text { máxima } \\
(\mathrm{mm})\end{array}$ & $\begin{array}{l}\text { Profundidad donde } \\
\text { viven }(\mathrm{m})\end{array}$ & Sitios arqueológicos \\
\hline Zidona dufresnei & 220 & $15-100 \mathrm{~m}$ & La Toma \\
\hline Olivancillaria sp. & 54 & $16-20 \mathrm{~m}$ & Arroyo Seco 1 \\
\hline Drupa pilsbry & 25 & 20-100 m \# & Cueva Tixi \\
\hline Drupa sp. & 60 & $<20 \mathrm{~m}$ & Cueva Tixi \\
\hline Adelomelon beckii & 490 & $10-75 \mathrm{~m}$ & Pintado II \\
\hline $\begin{array}{l}\text { Adelomelon (P.) } \\
\text { brasiliana }\end{array}$ & 200 & $18-70 \mathrm{~m}$ & $\begin{array}{l}\text { La Olla 1, El Palomar sitio 1, El Puente Sitio 1, Arroyo } \\
\text { Seco 2, La Toma, San Martín 1, Laguna Los Chilenos, } \\
\text { Casa de Piedra } 1\end{array}$ \\
\hline Adelomelon ancilla & 166 & $10-350 \mathrm{~m}$ & Paso Otero 3 \\
\hline Adelomelon sp. & $<150$ & $<10 \mathrm{~m}$ & $\begin{array}{l}\text { Puente de Fierro, Puente de Oriente, Don Aldo, L. Tapera } \\
\text { Moreira }\end{array}$ \\
\hline Urosalpinx haneti & - & - & Sitio Chenque I (material fósil) \\
\hline Buccinanops sp. & - & - & Sitio Chenque I (material fósil) \\
\hline Fisurella sp. & - & - & Sitio Chenque I (material fósil) \\
\hline Volutidae indet. & - & - & $\begin{array}{l}\text { La Toma, Laguna Sotelo, SA } 17 \text { Avestruz, San Martín 1, } \\
\text { Pintado II, Tapera Moreira } 1\end{array}$ \\
\hline $\begin{array}{l}\text { Mollusca indet. } \\
\quad \text { (marino) }\end{array}$ & - & - & $\begin{array}{l}\text { Bellamar } 1 \text { y 3, Nutria Mansa } 2 \text { sup, Paso Otero 3, Que- } \\
\text { quén Chico 1, Norte Cueva del Tigre, Cueva del Tigre, } \\
\text { Sur Cueva del Tigre, Arroyo Seco 2, Fortín Necochea, } \\
\text { Cueva El Abra, Don Aldo }\end{array}$ \\
\hline
\end{tabular}

Mesodesma mactroides (almeja amarilla), Donax hanleyanus (berberechos), Brachidontes (B.) rodriguezi (mejillín) y Tagelus plebeius (navajuela). Como se observa en la Tabla 2, estos ejemplares no han sido hallados en los sitios pampeanos relevados, donde predominan los gastrópodos sobre los bivalvos (véase más adelante). Existen dos excepciones (de Aparicio 1932; Frenguelli 1921) en las que se menciona la presencia de almeja amarilla en sitios arqueológicos superficiales de la faja costera.

Una situación inversa se presenta en zonas lindantes a la costa del área Interserrana, como son el litoral atlántico uruguayo y el norpatagónico donde dominan los bivalvos y se ha propuesto su consumo. En los sitios superficiales de ambos sectores sí se han recuperado grandes cantidades de ejemplares alimenticios que son de fácil acceso 
desde la playa. En el litoral atlántico uruguayo se han registrado grandes concentraciones antrópicas de Donax henleyanus asignadas al Holoceno Tardío (Castiñeira et al. 2004). En Norpatagonia los concheros están constituidos por Mesodesma mactroides, Brachidontes purpuratus, Brachidontes rodriguezi y Mytilus sp. (Bórmida 1969; Sanguinetti de Bórmida 1999).

A las diferencias entre las especies de los conjuntos pampeanos respecto de los de Norpatagonia y del Uruguay se le agregan dos características ambientales de la costa bonaerense que podrían haber afectado la explotación de moluscos. En primer lugar, en la costa del área Interserrana existe una escasa variación vertical entre la altura de la pleamar y la bajamar. Las mareas diarias poseen una media que varía entre 1 y $2 \mathrm{~m}$ de amplitud. Esto impide la exposición de extensas planicies y, por lo tanto, limita la productividad y el aprovechamiento de los recursos que se encuentran en la zona de mareas (Perlman 1980; Yesner 1980).

En segundo lugar, es necesario tener presente el tipo de sustrato disponible en la costa bajo estudio, dado que es uno de los factores principales que controlan el desarrollo de las comunidades bentónicas de moluscos. Las playas arenosas dominan ampliamente el litoral pampeano. En el sustrato arenoso la fauna de invertebrados marinos es menos abundante que en el rocoso. Este último, es escaso en la costa bonaerense, ya que sólo está presente en la zona rocosa de Cabo Corrientes en Mar del Plata y en las restingas de sedimentos consolidados distribuidas en forma discontinua a lo largo del litoral. En la línea actual de costa la mayoría de los fondos de piedra y los moluscos que viven en ellos se encuentran cubiertos por las aguas del mar (Aguirre y Farinati 2000).

Otro aspecto a tener en cuenta es que los moluscos puedan haber sido explotados en bajas cantidades y que no se hayan preservado sus exoesqueletos. Se ha planteado que la acidez de los sedimentos donde se encuentran depositadas acumulaciones poco densas de valvas limita fuertemente su preservación (Erlandson 2001). Sin embargo, en general, los sedimentos arenosos de la faja de médanos del área Interserrana presentan pH básicos (Federico Isla comunicación personal 2002), lo que en principio no apoya esa posibilidad.

Los moluscos marinos de los sitios de la región pampeana viven en la actualidad en zonas profundas, aunque no se puede descartar totalmente que debido a cambios en el nivel del mar y las corrientes marinas algunos de ellos hayan habitado en las cercanías de la playa en el pasado. Como se desprende de la Tabla 2, en los conjuntos arqueológicos se han recuperado moluscos de especies diversas (Figura 4) cuyo hábitat en la costa atlántica bonaerense se encuentra a batimetrías superiores a los $9 \mathrm{~m}$. Estas importantes profundidades, la variedad de especies observada y la ausencia de restos con alteración térmica no apuntan a una selección sistemática de determinados moluscos para su consumo.

Aun así, es necesario advertir que en otros sectores de su distribución geográfica, fuera de la región pampeana, cuatro de las especies registradas, Glycymeris longior, Amiantis purpurata, Olivansillaria sp. y Drupa pilsbry (aunque el tamaño de esta última es muy pequeño), se pueden localizar en aguas poco profundas afectadas por las mareas diarias. En uno de los entierros humanos del sitio arqueológico Arroyo Seco 2, ubicado a $60 \mathrm{~km}$ de la costa actual, se hallaron dos valvas articuladas de Amiantis sp. (Politis 1984), lo que podría señalar que este bivalvo fue juntado vivo en su hábitat acuático natural y transportado a través de varios kilómetros. Sin embargo, este hecho no indica necesariamente que este ejemplar haya sido recuperado vivo, ya que los tejidos que mantienen unidas las valvas son muy resistentes, tal como lo demuestra la presencia ocasional de valvas articuladas de bivalvos muertos sobre las playas o su registro en depósitos marinos antiguos. Por lo tanto, la mayoría de la información disponible indica que los moluscos marinos no tuvieron una clara relación con la subsistencia de los cazadores-recolectores pampeanos (véase también Berón 2004; Mazzanti y Valverde 2001; Politis et al. 2003); aunque, sobre la base de los datos discutidos, no se puede excluir completamente un consumo esporádico de la almeja amarilla o de algunas especies de los géneros Glycymeris, Amiantis y Olivansillaria que en el pasado vivieran más próximas a la playa que en la actualidad.

Los modos de aprovisionamiento de los gastrópodos y bivalvos que habitan aguas profundas pueden ser evaluados si se analizan los lugares en tierra firme donde se presentan. Los moluscos recuperados en los sitios pampeanos pudieron ser recolectados en dos lugares: la playa y los depósitos fósiles. Por un lado, en las playas 


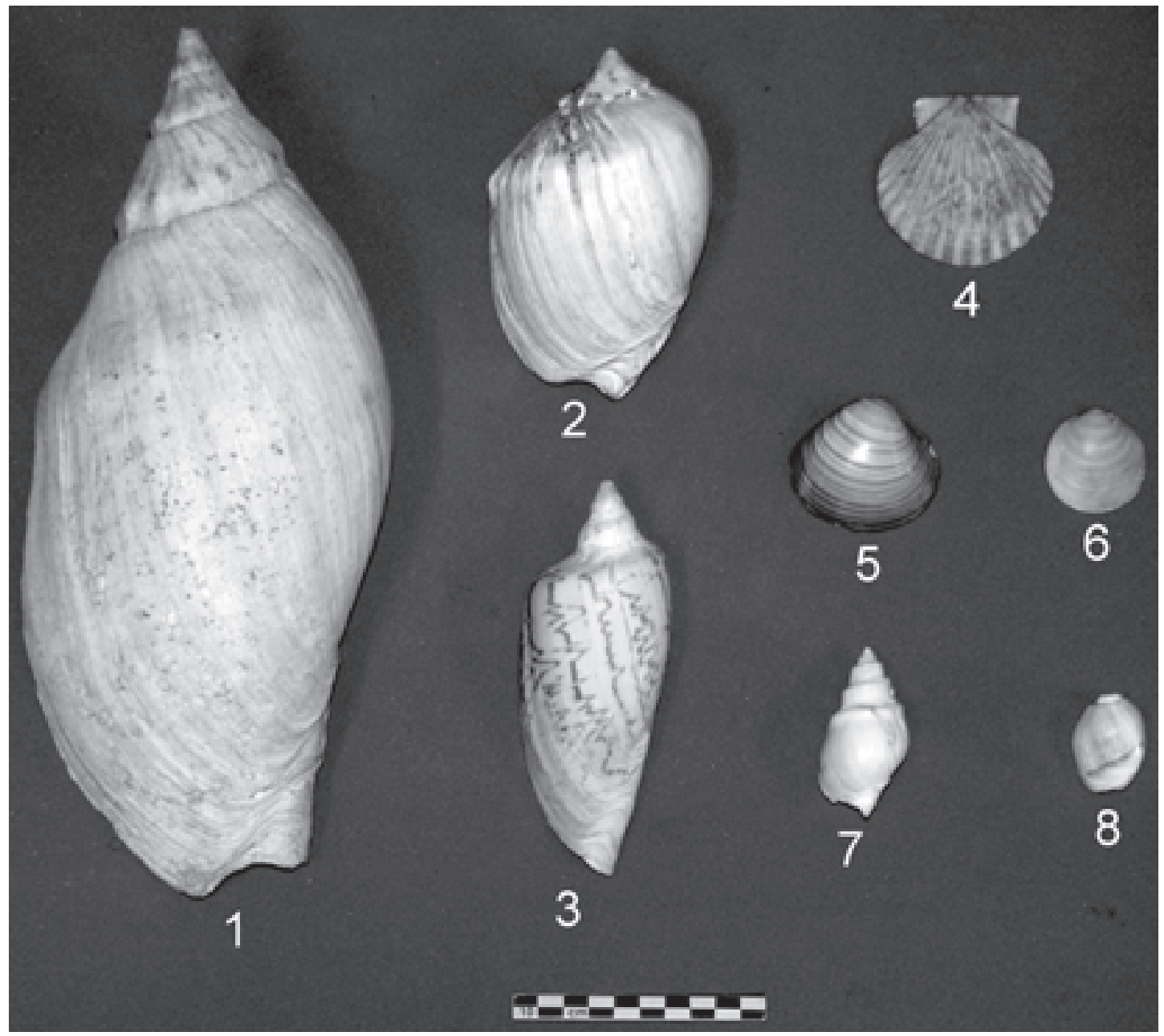

Figura 4. Ejemplares actuales de especies de gastrópodos y bivalvos representadas en los sitios arqueológicos de la región pampeana: (1) Adelomelon beckii; (2) Adelomelon brasiliana; (3) Zidona sp.; (4) Pecten sp.; (5) Amiantis purpurata; (6) Glycymeris longior; (7) Buccinanops sp.; (8) Olivancillaria sp.

Modern specimens of gastropods and bivalves species represented in the Pampean region archaeological sites: (1) Adelomelon beckii; (2) Adelomelon brasiliana; (3) Zidona sp.; (4) Pecten sp.; (5) Amiantis purpurata; (6) Glycymeris longior; (7) Buccinanops sp.; (8) Olivancillaria $s p$.

se hallan con frecuencia valvas aisladas. Luego de tormentas episódicas también pueden encontrarse allí algunos invertebrados marinos de zonas profundas con tejido blando aún adherido. $\mathrm{Si}$ bien algunos de estos ejemplares pueden hallarse con vida, la mayoría llega muerta a la playa como consecuencia del arrastre marino. En distintos sectores de la costa bonaerense se acumulan grandes cantidades de exoesqueletos transportados por las corrientes marinas y las tormentas episódicas. Estas concentraciones naturales de moluscos se registran en lugares relativamente estables, donde se pueden hallar los taxa observados en los conjuntos arqueológicos. Esto implicaría que estas acumulaciones u otras similares podrían ser áreas previsibles de abastecimiento de material malacológico.

Por otro lado, en las formaciones marinas situadas en las proximidades de la costa, como los cordones conchiles o las secuencias estuáricas que se formaron durante los episodios holocénicos de avance del mar, se presentan bivalvos y gastrópodos que pueden preservar la coloración, el brillo y el aspecto similar al de los especímenes vivientes (Aguirre y Farinati 2000). Por lo tanto, los depósitos marinos holocénicos pueden haber sido 
potenciales áreas de aprovisionamiento de moluscos fósiles, tal como se propuso para las cuentas sobre valvas halladas a $300 \mathrm{~km}$ de la costa en los contextos funerarios del sitio Chenque I (Cimino et al. 2004; Berón 2004).

De acuerdo a los datos actuales, es probable que la mayoría de los moluscos hallados en los sitios arqueológicos de la región pampeana no estuvieran disponibles en la zona de mareas. Esto implica la explotación de un recurso que, salvo excepciones, en el presente no puede obtenerse vivo desde la playa. Además, en el área Interserrana los sedimentos marinos holocénicos están constituidos fundamentalmente por depósitos estuáricos donde la acumulación de moluscos es baja. Por consiguiente, estas evidencias apoyarían la hipótesis de que los moluscos habrían sido recolectados muertos en el sector de playa, ya sea aislados o en concentraciones naturales, aunque no se descarta la alternativa de que en algunos casos fueran obtenidos vivos durante fuertes tormentas episódicas. Para avanzar sobre la posibilidad de que los moluscos fueran juntados muertos en la playa habría que analizar en cada sitio el grado y la uniformidad del rodamiento así como de los pulidos superficiales que muestran los mismos. En referencia a este punto es importante mencionar que en sitios ubicados a pocos kilómetros de la costa $(3,5 \mathrm{~km})$ como Nutria Mansa 1 sup (Bonomo 2004) y en aquellos más alejados (40 km) como Cueva Tixi (Mazzanti y Valverde 2001) se ha informado la presencia de ejemplares con evidencias de rodamiento.

Los moluscos pueden haber sido recolectados en función de las propiedades de sus exoesqueletos. En los sitios de la región pampeana no se registra una preferencia por un taxón en particular (Figura 5), sin embargo, la mayoría de los exoesqueletos corresponden a taxa de dimensiones considerables. Los moluscos más representados en los conjuntos son los gastrópodos del género Adelomelon ( $\mathrm{n}=14$ sitios), que es probable que hayan sido seleccionados por su tamaño y dureza. Otros gastrópodos y algunos bivalvos también pueden haber sido elegidos por su "decoración", brillo y coloración. Estas características pueden estar asociadas al uso de los moluscos como recipientes y para la manufactura de artefactos.

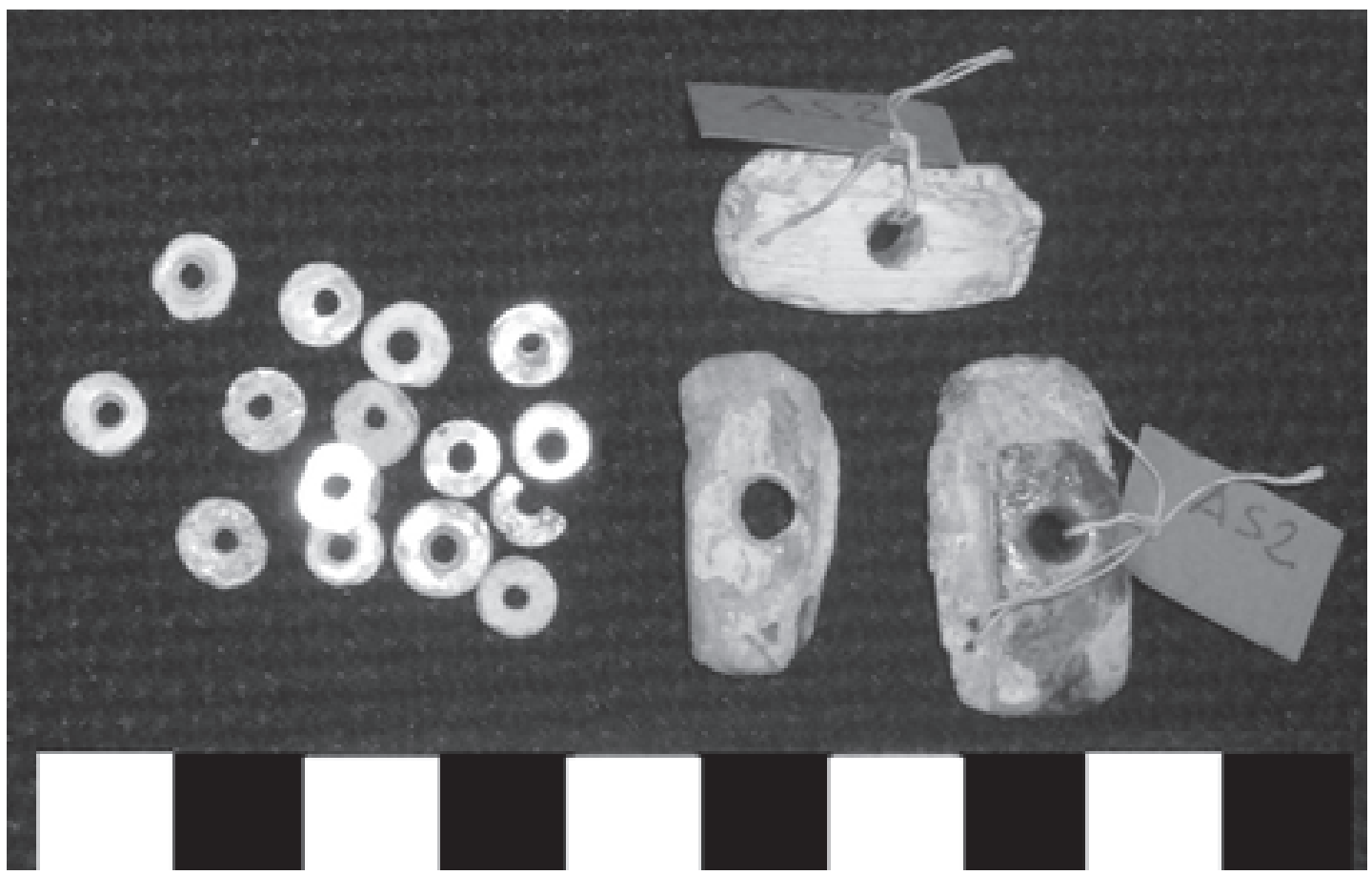

Figura 5. Cuentas circulares y subrectangulares manufacturadas sobre valvas halladas en asociación con esqueletos humanos en el sitio arqueológico Arroyo Seco $2($ escala $=10 \mathrm{~cm})$.

Circular and subrectangular bead shells found in association with human skeletons in the Arroyo Seco 2 archaeological site $($ scale $=10 \mathrm{~cm})$. 
Los moluscos marinos fueron empleados en otras partes del mundo como contenedores naturales $^{4}$ y como materia prima para la confección de elementos decorativos (Claassen 1998; Laporte 1998; Taborín 1993). En diecisiete sitios arqueológicos de la Pampa Húmeda han sido utilizadas distintas especies de moluscos (Fissurella sp., Urosalpinx haneti, Adelomelon brasiliana, Adelomelon sp., Volutidae indeterminado, Buccinanops sp., Amiantis purpurata, Amiantis sp., Bivalvia indeterminado) para la elaboración de posibles artefactos relacionados con propósitos ornamentales o utilitarios. En ocho sitios, localizados desde la faja de médanos hasta unos $200 \mathrm{~km}$ de distancia, se hallaron piezas con pulimento y/o retoques que fueron interpretadas como adornos (sitios Fortín Necochea $(\mathrm{n}=1)$ y Laguna Sotelo $(n=1)$; Crivelli Montero et al. 1987-88; Eugenio y Aldazabal 1987-88), perforadores, artefactos con muesca y con retoques o pseudorretoques y recipientes (sitios superficiales de la faja de médanos El Palomar $1(\mathrm{n}=1)$, El Puente $1(\mathrm{n}=1)$, Puente de Fierro $(n=1)$, Cueva del Tigre $1(n=1)$, Cueva del Tigre 4 (n=6); Austral 1965, 1994; Díaz de Chiri 1977; Loponte y Acosta 1986) y, en otros casos, sólo se menciona la presencia de modificación antrópica (sitio Pintado II; Petz y Saghessi 2000).

Es importante observar que agentes naturales, como el desgaste marino, pueden producir formas y pulidos similares a los generados por la acción humana. Hoy en día es frecuente hallar en las playas bonaerenses columellas de gastrópodos con formas punzantes, superficies pulidas y bordes redondeados. Estos elementos fragmentados producidos por la acción del oleaje y las corrientes en este ambiente de alta energía pueden mostrar atributos semejantes a los registrados en objetos de origen antrópico manufacturados por abrasión y/o pulido, por lo cual se considera que a futuro debe descartarse la intervención de agentes naturales sobre los elementos antes de definirlos como artefactos.

Asimismo, se manufacturaron cuentas que fueron empleadas como adornos corporales, para elaborar collares, pulseras y tobilleras. Las mismas se han recuperado en nueve sitios que se distribuyen desde la costa hasta unos $300 \mathrm{~km}$ de la misma: Arroyo Seco 2 (> 300; Politis 1984), El Abra $(n=2)$, Cueva Tixi $(n=4$; Mazzanti y Valverde 2001), Quequén Chico 1 ( $\mathrm{n}=1$; Madrazo 1972), San Martín 1 (n=2; Oliva et al. 1990), Laguna Los
Chilenos 1 ( $n=9$; Barrientos et al. 1997); Chenque I (> 800; Cimino et al. 2004; Berón 2004), Necochea (n=17; Vignati 1939) y Túmulo de Malacara (> 30; Vignati 1960) (Figura 5). La mayoría de estas cuentas y algunos moluscos sin modificación antrópica asociados a entierros humanos han sido hallados tanto en los contextos mortuorios de la costa, Túmulo de Malacara y Necochea, como de las llanuras interiores, Arroyo Seco 2, Chenque I $\mathrm{y}$, posiblemente, La Toma ( $\mathrm{n}=1$; Madrid y Politis 1991) y Fontezuelas ( $\mathrm{n}=1$; Hrdlicka 1912; véanse además referencias de Adelomelon brasiliana, Adelomelon ancilla y Zidona dufresnei asociadas a entierros humanos de Norpatagonia en Carcelles 1944). También es interesante mencionar que se han registrado cuentas y volútidos en estado natural con pigmentos adheridos a más de $40 \mathrm{~km}$ de la costa en Cueva Tixi ( $\mathrm{n}=1$; Mazzanti y Valverde 2001), Tapera Moreira 1 ( $n=1$; Berón 2004) y Casa de Piedra 1 (n=1; Gradín 1984).

En la región pampeana existen algunas evidencias sobre el proceso de producción de las cuentas. La presencia de cuentas en los sitios del interior es el resultado de distintas estrategias de aprovisionamiento, transporte y confección. La secuencia de manufactura de estos adornos incluye la formatización del fragmento, la creación de una abertura en el centro - generalmente con un perforador lítico ${ }^{5}-$, la abrasión de por lo menos parte del artefacto y el montaje (Claassen 1998; Laporte 1998; Taborín 1993). Por el momento, los contextos donde se registran restos de la elaboración de estos elementos son muy escasos. En Arroyo Seco 2, si bien fueron recuperadas cientos de cuentas, no se observaron rastros de uso en los instrumentos líticos atribuibles al trabajo sobre valva (Leipus 1997). En cambio, en el sitio San Martín 1 (Oliva et al. 1990) se ha planteado la existencia de indicios de fabricación de cuentas in situ con moluscos marinos.

\section{Consideraciones Finales}

En base a la información discutida en este trabajo se intenta demostrar que la utilización de los moluscos marinos en los sitios de la región pampeana no posee una clara vinculación con la dieta y que gran parte de estos elementos se han empleado para actividades no utilitarias. Esto se apoya en: (1) la ausencia de registros fehacientes de concheros en la zona de costa bajo estudio; (2) el 
registro de una gran diversidad taxonómica con formas distintas sin evidenciar la elección sistemática de especies comestibles accesibles desde la playa; (3) que la mayoría de los moluscos habrían sido recolectados muertos, dado que su hábitat se encuentra a profundidades considerables; (4) que los principales usos dados a las valvas fueron como materia prima de adornos corporales; (5) que se han utilizado algunos elementos fósiles; (6) la presencia de pigmentos en cuentas y gastrópodos sin modificación antrópica; (7) que se asocian habitualmente a contextos mortuorios y (8) que se han hallado a grandes distancias de la costa.

Estas evidencias indicarían que los grupos humanos que ocuparon el litoral pampeano no habrían tenido una estrategia orientada fuertemente a la explotación de moluscos marinos para su consumo. Teniendo en cuenta una escala suprarregional, este es un aspecto singular del litoral marítimo bonaerense en comparación con otras áreas del litoral atlántico sudamericano como el sur de Brasil, Uruguay y Norpatagonia donde se han registrado importantes densidades de bivalvos formando acumulaciones antrópicas.

Por último, como se ha visto anteriormente, en los conjuntos arqueológicos pampeanos han sido halladas cuentas sobre valvas y moluscos marinos con pigmentos adheridos. En la región los pigmentos han sido utilizados para las representaciones rupestres, para la decoración de los recipientes cerámicos y para cubrir a los muertos, lo que muestra la asociación de los moluscos con elementos que no se relacionan únicamente con actividades económicas y tecnológicas. Además, los moluscos han sido transportados a cientos de kilómetros de sus fuentes de origen. La importancia de este último hecho no reside solamente en la extensión de terreno por la que se acarrearon sino en sus posibles significados que condujeron a que fueran obtenidos por distintos grupos humanos que habitaban áreas geográficas separadas. Estas particularidades sumadas a la elección de estos adornos personales o de materiales sin modificar para ser dispuestos en distintos ajuares funerarios indican que los moluscos pudieron funcionar principalmente, aunque quizás no de manera exclusiva, como ítems con un marcado significado simbólico. De esta forma los colgantes compuestos por cuentas de moluscos pueden representar inscripciones culturales visibles en los cuerpos de los sujetos y por lo tanto vías no lingüísticas de comunicación social e ideacional.

Agradecimientos: este trabajo fue realizado gracias a los recursos de los proyectos: "Una perspectiva supra-regional de la arqueología del sudeste de la región pampeana" (UNLP, código N 503) y "Arqueología de las poblaciones indígenas del sudeste de la región pampeana desde un abordaje supra-regional” (PIP-CONICET 5424), ambos dirigidos por Gustavo G. Politis. Además, deseo expresar mi agradecimiento a Marina Aguirre por la información brindada acerca de la ecología de los moluscos marinos. A Gustavo Politis por sus valiosos comentarios sobre versiones anteriores de este trabajo. A los dos evaluadores anónimos que con sus sugerencias fortalecieron los argumentos de este artículo. A Alberto Cimino, Mónica Berón, Fernando Oliva y Luciano Prates por haberme facilitado información inédita de los sitios arqueológicos que están estudiando. A Clara Scabuzzo por la fotografía de las cuentas. A Heidi Luchsinger por su ayuda con la traducción del resumen. Todo lo expresado en este trabajo es responsabilidad del autor.

\section{Referencias Citadas}

Aguirre, M. y E. Farinati

2000 Moluscos del Cuaternario marino de la Argentina. Boletín de la Academia Nacional de Ciencias 64:235-333.

Ameghino, F.

1909 Las formaciones sedimentarias de la región litoral de Mar del Plata y Chapalmalán. Anales del Museo Nacional de Buenos Aires 17:343-428.

Austral, A.

1965 Investigaciones arqueológicas en el curso inferior del río Sauce Grande (Partido de Cnel. de Marina Leonardo
Rosales, Pcia. de Buenos Aires, República Argentina). Trabajos de Prehistoria 19:7-123.

1968 Prehistoria del sur de la región pampeana. Actas y Memorias del XXXVII Congreso Internacional de Americanistas Vol. III, pp. 325-338. UBA, Buenos Aires.

1994 Arqueología en el sudoeste de la provincia de Buenos Aires. Resúmenes del XI Congreso Nacional de Arqueología Argentina Tomo II, pp. 201-203. Museo de Historia Natural de San Rafael, San Rafael. 
Austral, A., C. Bayon, C. Deschamps, N. Priegue y M. Pérez Amat

1988 Sitio SA 17 Avestruz. Investigaciones arqueológicas en el partido de Saavedra, provincia de Buenos Aires. Resúmenes del IX Congreso Nacional de Arqueología Argentina, pp. 49. UBA, Buenos Aires.

Barrientos, G., M. Leipus y F. Oliva

1997 Investigaciones arqueológicas en la laguna Los Chilenos (Pcia. de Buenos Aires). En Arqueología Pampeana en la Década de los '90, editado por M. Berón y G. Politis, pp. 115-125. Museo de Historia Natural de San Rafael/INCUAPA, UNICEN, Olavarría-San Rafael.

Berón, M.A.

2004 Dinámica Poblacional y Estrategias de Subsistencia de Poblaciones Prehispánicas de la Cuenca Atuel-Salado-Chadileuvú-Curacó, Provincia de La Pampa. Tesis Doctoral, Facultad de Filosofía y Letras, UBA, Buenos Aires.

Bonomo, M.

2004 Ocupaciones Humanas en el Litoral Marítimo Pampeano: un Enfoque Arqueológico. Tesis Doctoral, Facultad de Ciencias Naturales y Museo, UNLP, La Plata.

2005 Costeando las llanuras. Arqueología del litoral marítimo pampeano. Sociedad Argentina de Antropología, Colección Tesis Doctorales, Buenos Aires.

Bormida, $\mathrm{M}$.

1969 El Puntarrubiense. Trabajos de Prehistoria 26:16-117.

Carcelles, A.

1944 Catálogo de los moluscos marinos de Puerto Quequén (República Argentina). Revista del Museo de La Plata 3:233-309.

Castiñeira, C., D. Panario, R. Bracco y O. Gutiérrez

2004 Nuevos aportes al estudio del registro arqueológico de la costa atlántica del Uruguay: acumulaciones antrópicas de berberechos. Actas del XIV Congreso Nacional de Arqueología Argentina. Universidad Nacional de Rosario, Rosario, en prensa.

Cimino, A., M. Guastavino y S. Velardez

2004 ¡Cuantas cuentas...! Elementos de adorno del sitio Chenque I, Parque Nacional Lihué Calel, provincia de La Pampa. En Aproximaciones Contemporáneas a la Arqueología Pampeana, editado por G. Martínez, M. Gutiérrez, R. Curtoni, M. Berón y P. Madrid, pp. 259-273. Facultad de Ciencias Sociales, UNCPBA, Olavarría.

Claassen, C.

1998 Shells. Cambridge Manuals in Archaeology, Cambridge.

Crivelli Montero, E., E. Eugenio y M. Silveira

1987-88 El sitio Fortín Necochea (partido de General La Madrid, provincia de Buenos Aires). El material de superficie. Paleoetnológica 4:7-37.

Crivelli Montero, E., E. Eugenio, U. Pardiñas y M. Silveira 1997 Archaeological investigation in the plains of the province of Buenos Aires, llanura Interserrana bonaerense, Quaternary of South America and Antarctic Peninsula 10:167-209.

de Aparicio, F.

1932 Contribución al estudio de la arqueología del litoral atlántico de la provincia de Buenos Aires. Boletín de la Academia Nacional de Ciencias de Córdoba 32:1-180.

Díaz de Chiri, M.A.

1977 "Informe preliminar sobre el yacimiento arqueológico Cueva del Tigre" (partido de Necochea, Pvcia. de Buenos Aires). Actas y Memorias del IV Congreso Nacional de Arqueología Argentina

Tomo II, pp. 59-68. Museo de Historia Natural de San Rafael, San Rafael.

d'Orbigny, A.

1999 [1829] Viaje a la América Meridional Tomo II. Emecé, Buenos Aires.

Erlandson, J.M.

2001 The archaeology of acuatic adaptations: paradigms for a new millennium. Journal of Archaeological Research 9:287-350.

Eugenio, E.O. y V.B. Aldazabal

1987-88 El sitio arqueológico Laguna de Sotelo-partido de Mar Chiquita, provincia de Buenos Aires, Paleoetnológica 4:79-86.

Figuti, L.

1993 O homem pré-histórico, o molusco e o sambaqui: considerações sobre a subsitência dos povos sambaqueiros. Revista do Museu de Arqueologia e Etnologia 3:67-80.

Frenguelli, J.

1921 Conchas de "Borus" en los paraderos indígenas del río San Roque (Sierra Chica de Córdoba, departamento de Punilla). Boletín de la Academia Nacional de Ciencias de Córdoba 26:404-418.

Gradín, C.J., editor

1984 Investigaciones Arqueológicas en Casa de Piedra. Dirección General de Cultura y Ente Ejecutivo Casa de Piedra, Pcia. de La Pampa.

Hrdlicka, A., editor

1912 Early Man in South America. Smithsonian Institute, Bureau of American Ethnology 52, Washington.

Isla, F.I.

1995 Holocene coastal evolution in Buenos Aires province, Argentina. Quaternary of South America and Antarctic Peninsula 11:297-321.

Jackson, D.S. y P.R. Báez

2005 Recursos litorales del semiárido de Chile: adaptaciones costeras durante el Holoceno. En Biodiversidad Marina: Valoración, Usos y Perspectivas ¿Hacia dónde va Chile?, editado por E. Figueroa, pp. 149-164. Editorial Universitaria, Santiago.

Laporte, L.

1998 Ornament production centres along the french atlantic coast during the Late Neolithic. En Craft Specialization: Operational Sequences and Beyond, editado por S. Milliken y M. Vidale, pp. 17-23. BAR International Series 720 , Oxford.

Leipus, M.S.

1997 Manufactura y uso de los artefactos líticos del sitio Arroyo Seco 2, partido de Tres Arroyos, provincia de Buenos Aires. Resúmenes del XII Congreso Nacional de Arqueología Argentina, pp. 24. Universidad Nacional de La Plata, La Plata. 
Lima, T.A.

1999-2000 Em busca dos frutos do mar: os pescadorescoletores do litoral centro-sul do Brasil. Revista USP 44:270-327.

Llagostera, A.

1992 Early occupations and the emergence of fishermen on the Pacific Coast of South America. Andean Past 3:87-109.

Loponte, D.

1987 Tecnotipología de Costa Bonita. Estudios de Antropología Pampeana 2:22-35.

Loponte, D. y A. Acosta

1986 Sitios acerámicos de la costa de Necochea. Estudios de Antropología Pampeana 1:3-47.

Madrazo, G.

1972 Arqueología de Lobería y Salliquelo (provincia de Buenos Aires). Etnía 15:1-18.

Madrid, P. y G. Politis

1991 Estudios paleoambientales en la región pampeana: un enfoque multidisciplinario del sitio La Toma. Actas del XI Congreso Nacional de Arqueología Chilena Tomo I, pp. 131-152. Museo Nacional de Historia Natural, Sociedad Chilena de Arqueología, Santiago.

Madrid, P., G. Politis, R. March y M. Bonomo

2002 Arqueología microrregional en el sudeste de la región pampeana argentina: el curso del río Quequén Salado. Relaciones 27:327-355.

Martínez, G.

1999 Tecnología, Subsistencia y Asentamiento en el curso medio del Río Quequén Grande: un Enfoque Arqueológico. Tesis Doctoral, Facultad de Ciencias Naturales y Museo, UNLP, La Plata.

Mazzanti, D.L. y C. Quintana, editores

2001 Cueva Tixi: Cazadores y Recolectores de las Sierras de Tandilia Oriental. 1 Geología, Paleontología y Zooarqueología. Laboratorio de Arqueología, UNMdP, Publicación Especial 1, Mar del Plata.

Mazzanti, D.L. y F. Valverde

2001 Artefactos sobre hueso, asta y valva. En Cueva Tixi: Cazadores y Recolectores de las Sierras de Tandilia Oriental. 1 Geología, Paleontología y Zooarqueología, editado por D. Mazzanti y C. Quintana, pp. 157-180. Laboratorio de Arqueología, UNMdP, Publicación Especial 1, Mar del Plata.

Mesa, A y D. Conlazo

1982 Resultados de una prospección en Claromecó (Pcia. de Buenos Aires, R.A.). Actas VII Congreso Nacional de Arqueología (1980), pp. 92-97. Montevideo, Uruguay.

Moreno, E.J.

2003 El Uso Indígena de la Costa Patagónica Central en el Período Tardío. Tesis Doctoral, Facultad de Ciencias Naturales y Museo, UNLP, La Plata.
Oliva, F., A. Gil y M. Roa

1990 Recientes investigaciones en el sitio San Martín 1 (BU/PU/5). Partido de Puán, provincia de Buenos Aires. Shincal 3:135-139.

Orquera, L.A. y E.L. Piana

1999 Arqueología de la Región del Canal Beagle (Tierra del Fuego, República Argentina). Publicaciones de la Sociedad Argentina de Antropología, Buenos Aires.

Perlman, S.M.

1980 An optimum diet model, coastal variability and hunter-gatherer behaviour. Advances in Archaeological Method and Theory 3:257-310.

Petz, R. y M. Saghessi

2000 Investigaciones arqueológicas en las lagunas Encadenadas del oeste, partidos de Adolfo Alsina y Guaminí (provincia de Buenos Aires). Póster presentado en el II Congreso de Arqueología de la Región Pampeana Argentina, Mar del Plata.

Politis, G.

1984 Arqueología del Area Interserrana Bonaerense. Tesis Doctoral, Facultad de Ciencias Naturales y Museo, UNLP, La Plata.

Politis, G., M. Bonomo y L. Prates

2003 Territorio y movilidad entre la costa atlántica y el interior de la región pampeana (Argentina). Estudios Ibero-Americanos 29:11-35.

Politis, G., P. Lozano y L. Guzman

1994 Evidencias de la ocupación humana prehispánica del litoral bonaerense en el sitio La Olla. Resúmenes XI Congreso Nacional de Arqueología Argentina Tomo II, pp. 240-241. Museo de Historia Natural de San Rafael, San Rafael.

Sandweiss, D., H. Mcinnis, R. Burger, A. Cano, B. Ojeda, R. Paredes, M. Sandweiss y M. Glascock

1998 Quebrada Jaguay: Early South American maritime adaptations. Science 281:1830-1832.

Sanguinetti de Bórmida, A.

1999 Proyecto Norpatagonia. Arqueología de la costa septentrional. Separata de los Anales de la Academia Nacional de Ciencias de Buenos Aires, pp. 1-35.

Taborín, Y.

1993 La Parure en Coquillage au Paléolithique. Gallia Préhistoire 29, CNRS, Paris.

Vignati, M.A.

1939 Los restos humanos y los restos industriales. En Historia de la Nación Argentina Tomo I, editado por R. Levene, pp. 163-200. Academia Nacional de la Historia, Buenos Aires.

1960 El indigenado de la provincia de Buenos Aires. Anales de la Comisión de Investigaciones Científicas de la Provincia de Buenos Aires 1:95-182.

Yesner, D.R.

1980 Maritime hunter-gatherers: Ecology and prehistory. Current Anthropology 21:727-750. 


\section{Notas}

1 Aquí el término ocupación se utiliza en un sentido amplio para englobar distintas categorías, como componentes, niveles, capas, ocupaciones y unidades, utilizadas por los arqueólogos pampeanos para separar conjuntos materiales asociados dentro de los sitios arqueológicos.

2 En la Figura 1 se agruparon las ocupaciones arqueológicas en intervalos de $10 \mathrm{~km}$ de acuerdo a la distancia de la costa. Por razones prácticas las ocupaciones de los tres sitios que superaban los $200 \mathrm{~km}(260,300$ y $450 \mathrm{~km})$ fueron incluidas en esta figura sin respetar los intervalos ubicados entre ellos (en los cuales no se registran elementos costeros).

3 En relación a la distancia, es importante agregar que recientemente se me ha comunicado de la existencia de otros cuatro sitios inéditos con moluscos marinos ubicados en la región pampeana. En estos sitios fueron recuperados restos de Adelomelon principalmente (Adelomelon brasiliana) a una distancia máxima de la costa de $510 \mathrm{~km}$ (Fernando Oliva comunicación personal 2005).

4 Véase este uso en poblaciones etnográficas de Norpatagonia en d'Orbigny (1999; II:301, 470 [1829]).

5 Es importante especificar que algunos moluscos pueden presentar perforaciones que no se deban a la actividad antrópica. Algunas especies, como por ejemplo la lapa Fissurella picta, poseen orificios propios de la valva que pueden ser utilizados para elaborar cuentas (Orquera y Piana 1999). Además, la bioerosión mecánica, causada principalmente por gastrópodos del género Natica, provoca orificios naturales en otros moluscos (Marina Aguirre comunicación personal 2002; véase también Claassen 1998:55-56) que también podrían haber sido aprovechados. 